\title{
Endogenous retroviruses in the origins and treatment of cancer
}

\author{
Natasha Jansz $^{1 *}$ and Geoffrey J. Faulkner ${ }^{1,2^{*}}$ (D)
}

\author{
* Correspondence: natasha.jansz@ \\ mater.uq.edu.au; faulknergj@gmail. \\ com \\ ${ }^{1}$ Mater Research Institute - \\ University of Queensland, TRI \\ Building, Woolloongabba, QLD \\ 4102, Australia \\ Full list of author information is \\ available at the end of the article
}

\begin{abstract}
Endogenous retroviruses (ERVs) are emerging as promising therapeutic targets in cancer. As remnants of ancient retroviral infections, ERV-derived regulatory elements coordinate expression from gene networks, including those underpinning embryogenesis and immune cell function. ERV activation can promote an interferon response, a phenomenon termed viral mimicry. Although ERV expression is associated with cancer, and provisionally with autoimmune and neurodegenerative diseases, ERV-mediated inflammation is being explored as a way to sensitize tumors to immunotherapy. Here we review ERV co-option in development and innate immunity, the aberrant contribution of ERVs to tumorigenesis, and the wider biomedical potential of therapies directed at ERVs.
\end{abstract}

\section{Introduction}

Endogenous retroviruses (ERVs) are uninvited and collectively indispensable residents in the human genome. Nearly $9 \%$ of our DNA is composed of identifiable ERVs [1] (Table 1). Most ERVs entered the germline via retroviral infection of a distant ancestor over 30 million years ago [3] and accumulated mutations at a neutral rate [4]. Some ERV protein-coding sequences have however assumed new and essential roles. The convergent evolution of placental Syncytin proteins is the foremost example of this, while others, such as Arc protein transaction of neuronal synapse plasticity, continue to emerge [5, 6]. More broadly, ERVs are a major source of gene regulatory innovation, as observed in the pluripotent cells of the early embryo [7-12], placental tissues [1315], the immune system [16-18], and other biological contexts [19-27]. Normal development, and the proper function of many cells and organs, therefore relies upon ERVs and their derivatives.

ERVs are retrotransposons, a type of transposable element (TE) that spreads throughout the genome via a copy-and-paste mechanism [28]. Three retrotransposon families (Fig. 1a) are mobile in humans: long interspersed element-1 (LINE-1, or L1), Alu (a type of short interspersed element, or SINE) and the composite element SINEVNTR-Alu (SVA, where VNTR stands for variable number of tandem repeats) [28]. Human ERVs (HERVs) (Fig. 1a) appear presently incapable of retrotransposition,

(c) The Author(s). 2021 Open Access This article is licensed under a Creative Commons Attribution 4.0 International License, which permits use, sharing, adaptation, distribution and reproduction in any medium or format, as long as you give appropriate credit to the original author(s) and the source, provide a link to the Creative Commons licence, and indicate if changes were made. The images or other third party material in this article are included in the article's Creative Commons licence, unless indicated otherwise in a credit line to the material. If material is not included in the article's Creative Commons licence and your intended use is not permitted by statutory regulation or exceeds the permitted use, you will need to obtain permission directly from the copyright holder. To view a copy of this licence, visit http://creativecommons.org/licenses/by/4.0/. The Creative Commons Public Domain Dedication waiver (http://creativecommons.org/publicdomain/zero/1.0/) applies to the data made available in this article, unless otherwise stated in a credit line to the data. 
Table 1 Intersection of RepeatMasker defined reference genome (hg38) ERV sequences with ENCODE candidate cis-regulatory elements [2]. Values in brackets represent fold-change compared to random sampling, with bold font highlighting > 50\% depletion (italicized) or enrichment (underlined). CTCF-bound elements have predicted insulator or looping function

\begin{tabular}{|c|c|c|c|c|c|}
\hline Family & $\begin{array}{l}\text { Reference } \\
\text { genome (\%) }\end{array}$ & $\begin{array}{l}\text { Promoter } \\
(\%, n=60,338)\end{array}$ & $\begin{array}{l}\text { Proximal enhancer } \\
(\%, n=141,830)\end{array}$ & $\begin{array}{l}\text { Distal enhancer } \\
(\%, n=667,599)\end{array}$ & $\begin{array}{l}\text { CTCF-bound } \\
(\%, n=56,766)\end{array}$ \\
\hline ERV & 8.860 & $8.472(1.0)$ & $6.124(0.7)$ & $12.786(1.4)$ & $17.317 \underline{(2.0)}$ \\
\hline LTR5Hs (HERV-K) & 0.019 & $0.008(0.4)$ & $\underline{0.032} \underline{(1.6)}$ & $\underline{0.037} \underline{(1.9)}$ & $0.014(0.7)$ \\
\hline LTR7 (HERV-H) & 0.031 & $0.028(0.9)$ & $\underline{0.054} \underline{(1.7)}$ & $\underline{0.118} \underline{(3.9)}$ & $0.037(1.2)$ \\
\hline LTR17 (HERV-W) & 0.016 & $0.017(1.1)$ & $0.008(0.5)$ & $0.012(0.8)$ & $0.012(0.8)$ \\
\hline
\end{tabular}

despite identification of polymorphic ERV insertions and HERV-K (HML-2) family copies with intact open reading frames (ORFs) [30, 31, 34-41]. Immobile ERVs, and particularly their flanking long terminal repeats (LTRs), can nonetheless contain promoter [21, 26, 27, 42-44] and enhancer elements [13, 16, 45], provide an extensive repertoire of transcription factor binding sites [46-48], and attract DNA and histone modifying complexes [49-54]. These features imbue ERVs with substantial capacity to regulate the expression of gene networks required for normal cell function. Indeed, the apparent frequency of ERV domestication is sufficient to support proposed models of predominant ERV cooperation, rather than escalating conflict, with the host genome [19, 22, 24, 33, 54, 55].

ERVs may elicit local and genome-wide transcriptional responses that result in immune activation in the context of disease, and ERV-derived regulatory elements govern aspects of the interferon response integral to innate immunity [16]. At present, the use of epigenetic therapies to induce ERV activation and downstream immune signalling in tumor cells, even if mechanistically unresolved, holds significant clinical potential [56, 57]. The motivation for this review is to dissect and disseminate recent evidence of ERV-associated oncogenesis, with emphasis on emerging therapies that target ERVs.

\section{A human ERV census}

The reference genome assembly contains nearly 450,000 ERV-derived sequences stratified into nearly 100 families based on common features [1]. All ERV families discovered in humans were subsequently found in other primates, although some younger HERV loci are not conserved in other species [36, 38]. An intact HERV provirus is minimally composed of 5' and 3' LTRs flanking an internal Gag-Pro-Pol polyprotein-coding sequence [58] (Fig. 1a). Gag is cleaved by the protease (Pro) to generate viral particle structural proteins, whereas Pol encodes reverse transcriptase, integrase, and ribonuclease $\mathrm{H}$ enzymatic activities. Although HERVs can contain a remnant envelope (Env) gene, and other accessory genes, they are in general not infectious [59-61] and, due to germline ORF mutations, also lack potential for intracellular mobility. There is evidence for ongoing ERV retrotransposition in other mammals [62, 63]. In mouse, intracisternal A-type particle (IAP) ERVs are devoid of a functional Env gene and lack the capacity for virion formation and reinfection, but have become capable of retrotransposition via the formation of intracellular particles [63]. There is no evidence for such an adaptive process occurring in humans, with the possible exception of the HERV-K family. The reference genome contains at least 600 annotated HERV-K copies [30, 31] and population-scale analyses have found up to six polymorphic HERV-K loci per 


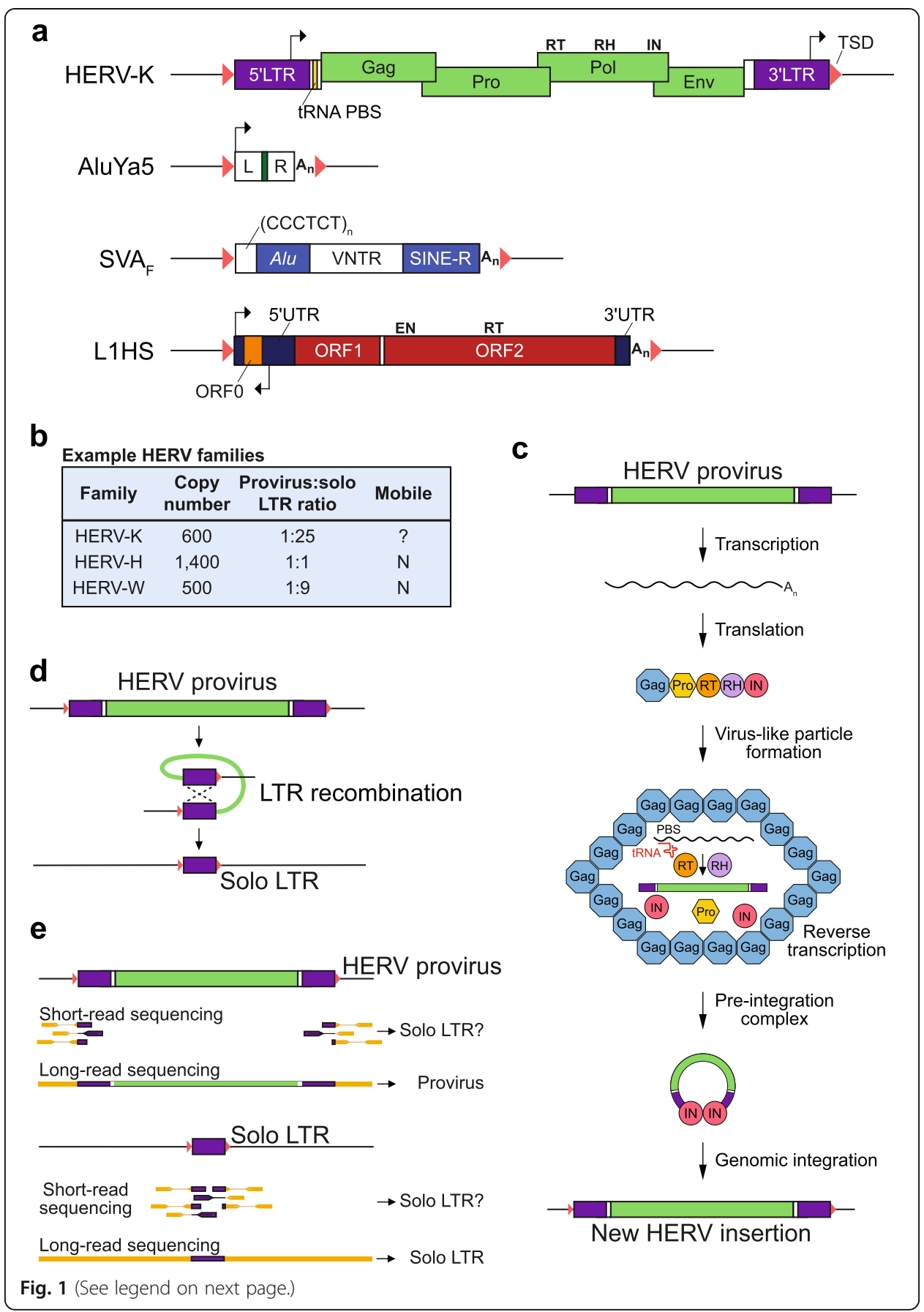


(See figure on previous page.)

Fig. 1 Human transposable elements. a HERV-K, AluYa5, SVAF and L1HS (L1 human-specific) are the youngest human ERV, Alu, SVA, and L1 families, respectively. New retrotransposition events are flanked by hallmark target site duplications (TSDs, pink triangles). HERV-K is $\sim 9 \mathrm{kbp}$ in length, contains a tRNA reverse transcription primer binding site (PBS), and encodes overlapping Gag, Pro, Pol, and Env ORFs. Amongst other features, $P$ ol incorporates reverse transcriptase $(R T)$, ribonuclease $H(R H)$, and integrase (IN) activities. AluYa5 ( 280 bp) is composed of left $(L)$ and right $(R)$ monomers divided by an adenosine-rich region and is followed by a polyadenine tail $\left(A_{n}\right)$. SVA $(\sim 2 \mathrm{kbp})$ is a composite element that brings together a variable number of CCCTCT hexamers, an Alu-like sequence, a variable number tandem repeat (VNTR) region and SINE-R, a sequence strongly resembling a portion of the HERV-K Env gene and 3' LTR. L1HS ( 6 kbp) is the only autonomously mobile human TE. It encodes two sense ORFs (ORF1 and ORF2) and an antisense ORF (ORF0) that may boost its mobility [29]. ORF2p possesses endonuclease (EN) and reverse transcriptase (RT) activities. Black arrows indicate known promoter elements. Elements are not depicted to scale. b HERV family statistics [30-32]. c HERV retrotransposition model, adapted from [33]. A provirus mRNA is transcribed and translated into a Gag-Pro-Pol fusion protein. Gag is cleaved by Pro to generate a virus-like particle, containing the fusion protein and ERV mRNA. A specific tRNA binds the primer binding site (PBS) to promote reverse transcription, producing a CDNA. The CDNA forms a complex with integrase (IN) to integrate into a new genomic site. d Internal homologous recombination events can occur between $5^{\prime}$ and 3' LTRs, resulting in loss of the provirus internal region and one LTR, to generate a solo LTR. e Long- and short-read sequencing approaches differ in their ability to discriminate HERV proviral and solo LTR alleles

individual genome, including rare HERV-K proviruses with a full complement of intact Gag, Pro, Pol, and Env ORFs [9, 30, 31, 35-40, 60] (Fig. 1b). Reconstructed HERV-K lineage progenitor elements are infectious in vitro [60, 64, 65], and endogenous HERV$\mathrm{K}$ mRNAs and proteins may be expressed in germline cells [9, 66, 67]. Genomic analyses of familial trios have not, however, recorded any robust de novo HERV-K insertions. HERV-K is therefore at most mobile under extremely limited settings, for instance due to reactivation of infectious HERV-K viral particles.

L1 facilitates all endogenous retrotransposition in human cells, including that of $A l u$, SVA, and other cellular RNAs [28] (Fig. 1a). L1 and HERVs were at some point likely both mobile in modern humans $[35,68]$ and each family may occasionally assist the other to retrotranspose [32, 69]. HERV LTR and L1 5' UTR promoters can each drive transcription of adjacent genes [21, 70, 71]. However, L1 and HERVs differ in their retrotransposition strategies and potential cis-regulatory impact. As expected for a retroviral provirus, HERV mRNA transcription appears to mainly initiate toward the 3' end of the 5' LTR [72] and is followed by cytoplasmic reverse transcription (Fig. 1c). Whereas HERV insertions are depleted from gene-rich regions, particularly those in the same orientation as the host gene, reconstructed HERV-K proviruses exhibit moderate preference for intragenic integration [64, 65, 73]. By contrast, L1 mRNA transcription is mainly initiated from the first nucleotide of its 5' UTR, and reverse transcription leading to L1 integration is primed from the nuclear genome [72, 74]. The L1 endonuclease has no apparent preference for gene-rich regions, and senseorientated intragenic L1 insertions are more likely to be deleterious than their antisense counterparts [75]. HERV and L1 transcriptional regulation, as well as their retrotransposition-mediating protein complexes, are therefore distinct, even if in some situations they may be targeted by the same host defense pathways [76]. A further important consideration is that less than $2 \%$ of reference genome L1s retain a $5^{\prime}$ UTR, owing to the prevalence of L1 5' truncation during integration. For these reasons, even if HERVs are presently immobile, they are arguably more likely than L1 to perturb gene regulation. 
At least $85 \%$ of reference genome ERV instances are solitary (or "solo") LTRs [1, 4, 31]. Solo LTRs arise from homologous recombination between ancestral 5 ' and 3' proviral LTRs, where the intervening protein-coding sequence is deleted [31, 41, 77] (Fig. 1d). Most ERV families are almost exclusively composed of solo LTRs and, amongst HERVs, these genome structural variants are still occurring. HERV-K and older HERV-H and HERV-W alleles present as a provirus in some individuals, and as a solo LTR in others, have been documented [31, 38, 39, 41]. These variants have the potential to perturb gene regulation, for instance by attracting repressive complexes [78] or, as exemplified by the pluripotency marker ESRG, remove exons overlapping a HERV internal sequence from a transcriptional unit [11, 31]. Given that solo LTRs and proviral LTRs can be difficult to distinguish with short-read sequencing [37] (Fig. 1e), the uptake of long-read technologies $[79,80]$ by cancer genomics and population resequencing consortia is likely to substantially expand the number of cataloged polymorphic solo LTRs. Although likely to be rare, these may include disease-associated variants.

\section{ERV wiring of developmental transcription networks}

The relevance of ERVs to pathogenesis is underscored by their contributions to normal development and human biology. HERV-derived regulatory elements are bound by transcription factors and activated during preimplantation development modelled in vitro [9, 20, 81, 82] (Table 1). Presumably, this aided the retroviral ancestors of HERVs in being expressed and endogenously amplified once they had accessed the germline [33]. HERVs display distinct, embryonic stage-restricted transcriptional profiles [83] and can harness transcription start sites to adjacent genes [21, 44]. For instance, HERV-L elements are upregulated during embryonic genome activation and can be bound by the transcription factor DUX4 to serve as alternative promoters for cleavage stage genes [84]. Dux, the functional murine orthologue of DUX4, binds the related mouse ERV family, MERV-L [84, 85]. MERV-L provides numerous alternative promoters for genes expressed at the 2-cell stage, when mouse embryonic transcription begins [86-88]. HERVs contribute exons to long noncoding RNAs, such as ESRG, HPAT5, and linc-ROR, which are upregulated by OCT4 and other pluripotency factors and may in turn act as molecular sponges for miRNAs limiting pluripotency factor expression [7, 8, 11, 89, 90]. The trophoblast cells of the placenta also express ERVs. For example, a primate MER21A LTR inserted upstream of the CYP19A1 aromatase gene promotes transcriptional initiation of a highly abundant and placenta-specific CYP19A1 mRNA (Fig. 2a) [15, 26]. CYP19A1 generates 0.3\% of the capped mRNA found in human placental tissue, and yet is not expressed in the non-primate placenta $[15,91]$. ERVs in sum provide an extensive catalog of alternative and canonical transcription start sites for genes expressed in early development, many of which are human-specific [21, 44].

Beyond serving as promoters during early development, HERV-H and HERV-K sequences appear to more frequently behave as enhancers (Table 1). The genome contains an estimated 800,000 elements bearing an enhancer biochemical signature [2], although only a fraction of these have been functionally validated as bona fide enhancers [92]. Enhancers may regulate both proximal and distal genes, and as enhancerassociated noncoding RNAs are widespread, the mechanisms by which enhancers 


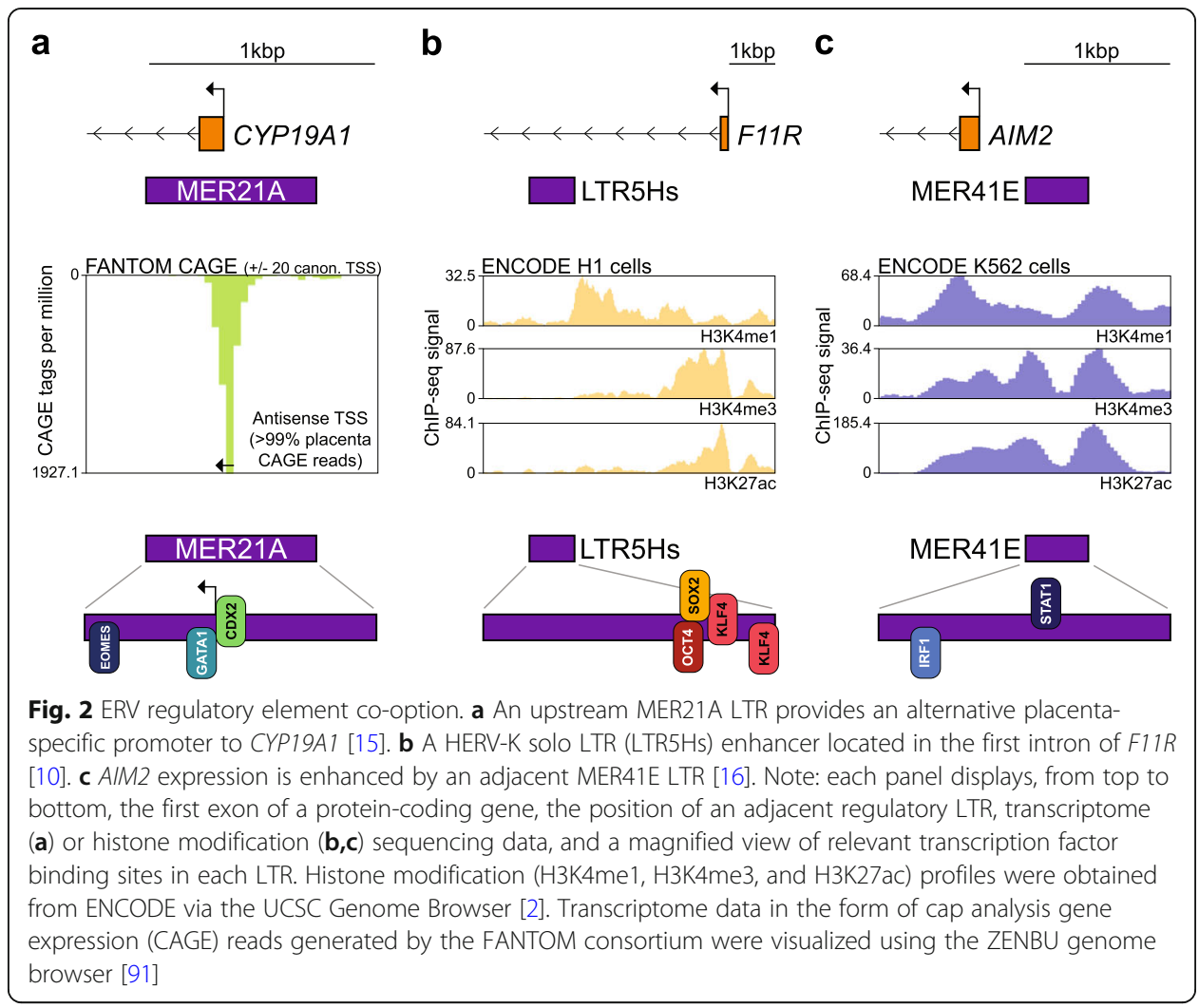

influence gene expression are often not straightforward to resolve [92]. Candidate enhancer elements are disproportionately likely to overlap HERV-H sequences (Table 1). HERV-H copies are highly transcribed in the pluripotent cells of the blastocyst [7, 9, 11] and demarcate boundaries of open chromatin [12]. CRISPR-Cas9 mediated deletion or repression of HERV-H loci can alter the expression of upstream genes in the same topologically associated domain, in line with HERV-H copies often functioning as enhancers over longer genomic distances (Table 1) [10, 12]. HERVs supply transcription factor binding sites to the network of regulatory elements governing pluripotency $[9$, 10, 33, 93, 94]. By example, the consensus HERV-K LTR (LTR5Hs) harbors an OCT4 binding site, and in embryonic stem cell cultures, OCT4 directly binds and transactivates DNA hypomethylated LTR5Hs sequences [9]. HERV-K transcription, in contrast to HERV-H, begins in the embryonic genome at the 8-cell stage [9, 93]. However, as per HERV-H, HERV-K can provide proximal and distal enhancers (Table 1). One such example is an intronic HERV-K LTR enhancer of the pluripotency marker gene F11R [10] (Fig. 2b). Concomitant with the global acquisition of somatic heterochromatin, HERV transcription is downregulated post embryonic implantation [12, 93]. Although further work is needed to understand the developmental function and dispensability of HERV expression in vivo, it is clear that HERV regulatory elements are intimately and reciprocally linked with early embryonic development.

Despite their global postimplantation downregulation, some ERV families are predicted to contribute to lineage-specific enhancer networks [13, 25]. In particular, ERV cis-regulatory elements facilitate the interferon gamma (IFNG) response [16, 17, 20, 95] with the primate-specific MER41 family being the best characterized example [16, 96]. 
MER41 can harbor binding motifs for the transcription factors IRF1 (interferon regulatory factor 1) and STAT1 (signal transducer and activator of transcription 1) [16, 96]. Upon IFNG induction, some MER41 copies are bound by STAT1 and IRF1 and exhibit H3K27ac enrichment, a property of active enhancers [2, 16, 91, 96]. In a seminal 2016 study, Chuong et al. found a MER41 element immediately adjacent to AIM2, which encodes an interferon-stimulated protein that detects double-stranded DNA (dsDNA) upon viral or bacterial infection, and one that can elicit an inflammatory response [97]. Crucially, the MER41 sequence contained the only STAT1 binding motif within $50 \mathrm{kbp}$ of AIM2 (Fig. 2c). CRISPR-Cas9 deletion of this MER41 instance prevented AIM2 expression following IFNG induction and diminished the downstream inflammatory response. As well, Chuong et al. observed attenuated expression of several other interferon response genes upon deletion of nearby MER41 copies, suggesting recurrent co-option of this ERV family as IFNG-inducible proximal enhancers [16]. MER41 has also been found to participate in long-range chromatin interactions with genes involved in the IFNG response, raising the possibility that MER41 copies can act as distal enhancers [98]. The contribution of MER41 to IFNG signalling elucidated by Chuong et al. provides clear precedent for ERVs shaping somatic transcriptional networks [95] and offers a framework by which ERV regulation could be probed and manipulated elsewhere.

\section{Pathways to modulate ERV activity}

Host genomes maintain numerous systems to modulate ERV activity, as thoroughly reviewed elsewhere [51, 76, 99, 100]. Here we will briefly focus on the ERV control mechanisms that presently show the most potential as targets for genetic or pharmacological therapies (Table 2). Programmed mammalian ERV repression is enacted through the interconnected PIWI-interacting RNA (piRNA), DNA (CpG) methylation, chromatin packaging, and KAP1 (TRIM28) pathways, amongst others [76, 111]. piRNAs are predominantly found in male germ cells and function to silence TEs, in part, by recruiting DNA methylation [112, 113]. PIWI proteins are necessary for de novo DNA methylation of ERVs during male gametogenesis [112, 114, 115]. piRNAs are generally not encountered in mammalian somatic cells $[113,116]$. In the embryo, KRABZinc Finger Protein (KZFP) binding initiates silencing of ERVs and other TEs [52, 54, 117]. Some 350 KZFPs show highly orchestrated expression patterns that parallel ERV expression dynamics $[22,49,52-54,93,118]$. Specific KZFPs directly bind individual ERV copies and elicit silencing through recruitment of KAP1. KAP1 is a scaffold protein that engages effectors involved in heterochromatin formation [52, 119, 120]: the histone H3, lysine 9-specific methyltransferase SETDB1; the nucleosome remodelling and deacetylation (NuRD) complex; heterochromatin protein 1 (HP1); and DNA methyltransferases [121-124]. Notably, each of these effectors can serve as an enzymatic target for the therapeutic modulation of ERV activity. Following their deposition in the embryo, DNA methylation and H3K9me3 work in concert to ensure stable and permanent ERV repression [52, 119, 125].

KAP1-mediated ERV silencing is robust yet not universal. Recent long-read methylome data generated from adult tissues suggest DNA methylation is lower at HERV-K elements than at other recently-mobile TEs or non-TE sequences [79]. HERV-K copies are unusually likely to present tissue-specific chromatin marks consistent with active 


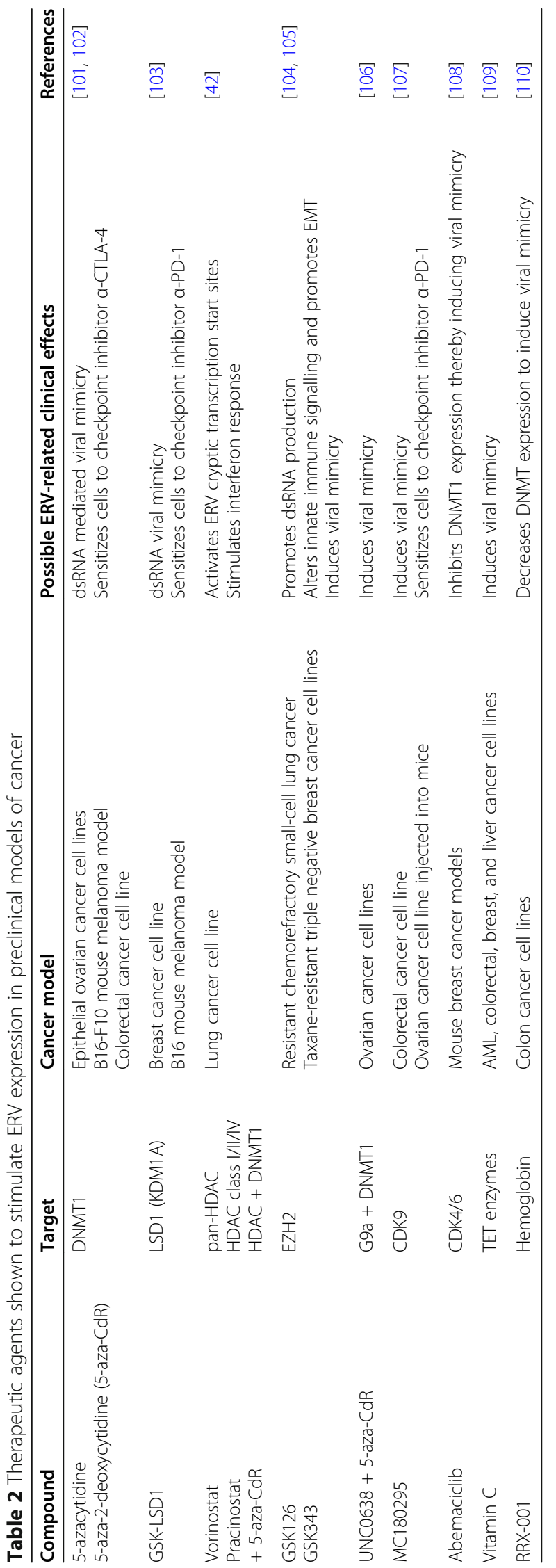


regulation [126]. More generally, ERVs can promote tissue-specific transcription regulated by KZFPs in a wide range of normal tissues [15, 21, 22, 26, 53, 54, 70, 127, 128]. Many KZFP binding sites are also bound by tissue-specific transcription factors and display biochemical hallmarks of enhancers [54]. Furthermore, in T cells, KAP1 corepressor binding is differentially maintained across subsets of repressed ERVs [18]. These data collectively lend themselves to an extended model of KAP1 silencing in which lineage-specific KZFP expression facilitates tissue-specific ERV control and domestication [22, 53, 54]. KAP1-mediated repression is therefore an appealing target to precisely modulate ERV activity, especially as CRISPR-dCas9 fusion proteins have proven adept for this purpose in vitro [10, 12, 45, 92, 93].

\section{A complex interplay between ERVs and innate immunity}

New viral infections, ERVs, and the innate immune system, coincide in vivo. Exogenous retroviruses can drive pathogenesis directly by insertional mutagenesis or introducing new regulatory elements, and indirectly by activating ERVs $[43,45,129,130]$. A major cause of liver cirrhosis and hepatocellular carcinoma, for example, is hepatitis B virus (HBV) infection. In liver tumor genomes, HBV integrants can provide oncogenic enhancers and promoters, alongside an overarching epigenomic landscape that fails to repress TEs [43, 79, 131-133]. Infection leading to chronic inflammation and disease is in the liver, and in many other contexts, a well-established aetiological paradigm, with ERVs proposed to impact immune physiology and pathology [134]. ERV expression is also associated with inflammatory diseases of the central nervous system, including multiple sclerosis and amyotrophic lateral sclerosis, as discussed in detail elsewhere [135-137]. For the purpose of this review, we will focus on the convergence of innate immune signalling pathways and ERV expression products, which is relevant when considering ERV activity in tumors.

ERVs sit at the interface of self:non-self recognition. In what has been called viral mimicry, ERV expression can elicit host cell immune signalling via induction of viral defense pathways [101, 102, 134, 138]. One proposed explanation for this immune response is the recognition of ERV Env proteins and dsRNAs by pattern recognition receptors (PRRs) $[139,140]$. Many exogenous viruses produce dsRNA at some stage of their replication cycle. Viral defense pathways are activated when PRRs recognize socalled pathogen-associated molecular patterns (PAMPs), such as dsRNA, and initiate immune signalling [141]. dsRNA is sensed by endosomal TLR3 and cytosolic MDA5MAVS pathways, activation of which results in the induction of type I and type III interferon signalling and increased immunogenicity [142]. Induction of interferon signalling may initiate a positive feedback loop, in which ERVs can be bound and activated by immune effectors such as STAT1, IRF1, and NFkB, exacerbating ERV expression and the interferon response [16, 95, 96, 134, 143]. ERV protein products can also trigger proinflammatory cytokine signalling via TLR4, which is sustained by a positive feedback loop of HERV expression, further TLR4 activity, and chronic inflammation [139]. In mouse, ERV reactivation has been observed when immune signalling pathways are perturbed, upon deletion of nucleic acid sensors TLR7, TLR3, and TLR9 [134, 140] and in immunodeficient animals [138]. The interconnected nature of this regulation demonstrates a key point: because ERVs are so entwined in the innate immune system, 
their contributions to pathogenesis, as causal agents or bystanders upregulated by inflammation, are difficult to untangle.

\section{ERV-mediated oncogenesis}

Tumorigenesis significantly resembles the corrupt reversion of cells to an earlier developmental state [144]. As for the preimplantation embryo, TE reactivation is seen in many cancers and can influence tumor genome stability [125, 145-150]. Extensive chromatin remodelling occurs upon malignant transformation. DNA methylation is redistributed across the genome and, in general, TEs are hypomethylated [79, 132, 145]. However, TEs do not all adhere uniformly to these trends. Recent analyses suggest a significant cohort of individual TE copies, including ERVs, are consistently unchanged, or more methylated, in cancer than in the corresponding normal cell type [79]. Perhaps these ERVs are influenced unexpectedly by another layer of epigenetic control $[53,109,119,125]$ or are already hypomethylated prior to tumorigenesis [79, 126, 132, 150, 151]. These observations have two major implications. Firstly, any cancer therapy intended to target ERV families must consider that each of its copies, including those proximal to key cancer genes, may not behave in the same way. Secondly, as epigenetic repression may be more, or less, enforced on each ERV locus, the accessible complement of ERV regulatory elements is changed, making both tumor suppressor gene downregulation and oncogene upregulation possible at a time and place that alters the course of disease $[43,45,127,143,144,152,153]$.

In tumors, reactivated TEs can promote oncogene expression, contributing to disease progression in a phenomenon termed onco-exaptation [152]. Again, much like in development, ERVs can serve as alternative promoters for nearby genes in malignant cells (Fig. 3a) $[127,152,157,158]$ and cryptic transcription start sites within ERVs can be employed to produce aberrant protein-coding mRNAs, including those with novel ORFs [42, 157]. Analyses of many cancer types suggest TE onco-exaptation is relatively common $[43,45,127,133,152,159]$. This is well demonstrated by an upstream MaLR (THE1B) LTR sequence providing an alternative promoter to CSF1R in Hodgkin's lymphoma, a B cell cancer [143]. In healthy myeloid cells, CSF1R is under the control of its canonical promoter and an intronic enhancer bound by the transcription factor PU.1. In Hodgkin's lymphoma cells, CSF1R is upregulated, despite absence of PU.1 [143]. As resolved by Lamprecht et al., loss of DNA methylation and downregulation of the corepressor CBFA2T3 alleviates THE1B repression, allowing it to initiate transcription of an aberrant CSF1R mRNA [143]. Furthermore, Lamprecht et al. found the THE1B promoter was activated by NFKB binding, highlighting the synergy between chromatin pathways and ERV transactivators.

Alongside alternative promoter function, ERVs may also be onco-exapted as enhancers, as recently shown by Deniz et al. in an elegant study of acute myeloid leukemia (AML) [45]. Here, an initial epigenomic survey in AML samples returned a number of differentially accessible ERV families, including HERV-K, marked with H3K27ac and H3K4me1 and bound by AML-associated transcription factors, raising the possibility of enhancer function (Fig. 3a) [45]. CRISPR-Cas9 deletion of several ERVs in vitro downregulated adjacent AML-expressed genes. Importantly, targeted CRISPR-dCas9 mediated silencing of LTR2B, the candidate ERV (HERV-E) family exhibiting the greatest AML-restricted accessibility, led to impaired cell growth in AML cell 


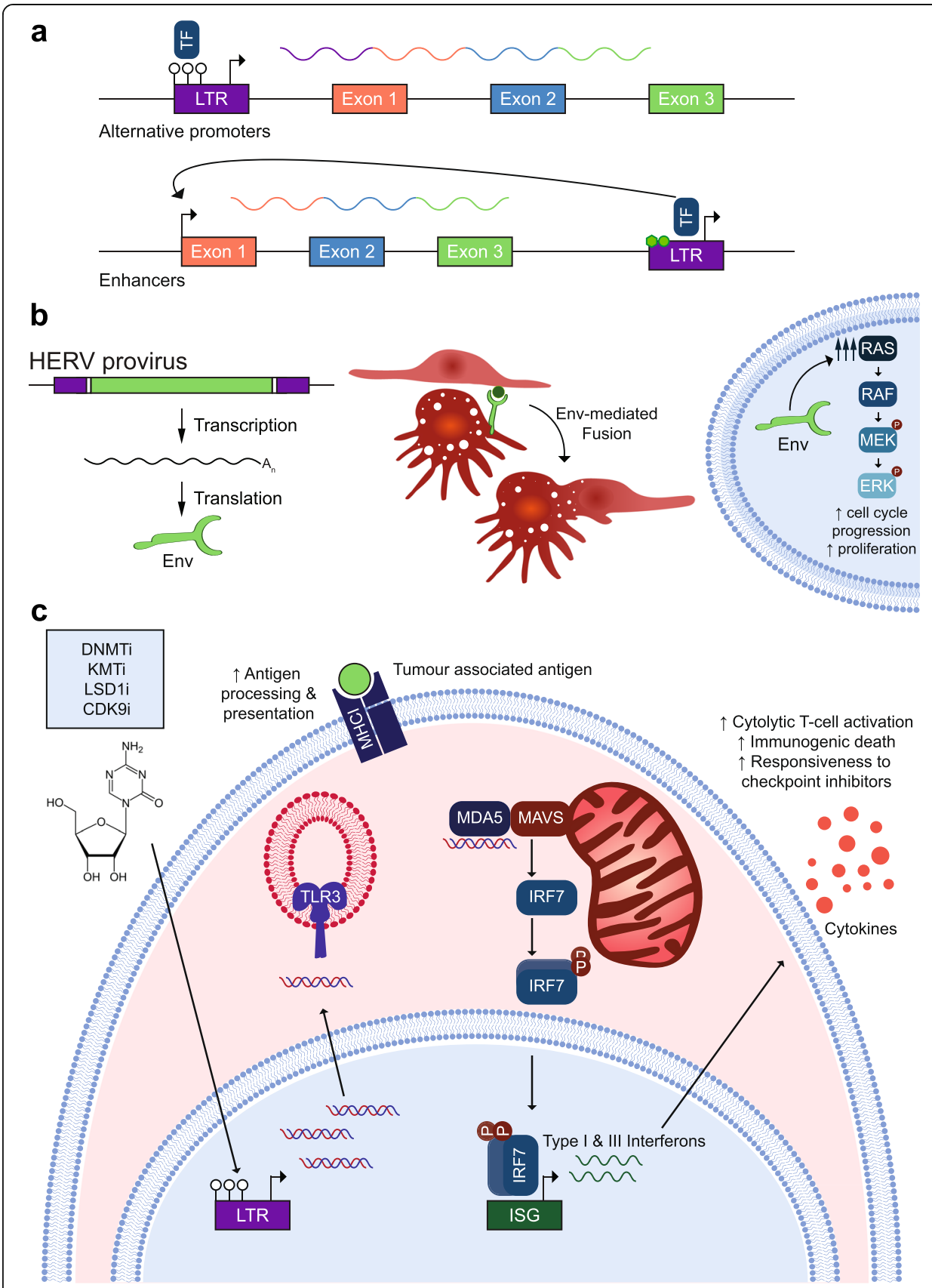

Fig. 3 (See legend on next page.) 
(See figure on previous page.)

Fig. 3 ERVs contribute to oncogenesis and may be targeted therapeutically. a Onco-exapted ERVs can regulate host gene expression in tumors. Hypomethylated ERV LTRs can be bound by transcription factors (TF) and serve as alternative promoters to induce the expression of oncogenes contributing to oncogenesis (top). They may also be decorated with H3K27ac and H3K4me1 (light green) and act as enhancers to drive the expression of adjacent or distal genes (bottom). Note: empty white circles represent unmethylated CpG dinucleotides. b HERV proteins, such as Env, can be expressed from intact HERV provirus ORFs in cancer cells (left). In breast and endometrial carcinoma models, Env has been detected on the cell membrane and is able to mediate cellular fusion with endothelial cells [154, 155] (middle). Env can promote tumorigenesis, for example by stimulating the RAS/RAF/MEK/ERK pathway in breast cancer models [156]. c Proposed model for therapeutic targeting of ERV-induced viral mimicry to promote immune detection of tumor cells. ERV reactivation can be induced by a number of therapeutic agents that target chromatin modifying enzymes (blue box). Derepression of ERV LTRs results in the production of dsRNA molecules, which can be detected by cytosolic dsRNA sensors TLR3 and MDA5 [101, 102, 134]. MDA5 binds to MAVS in the mitochondria and stimulates a signalling cascade which promotes the phosphorylation, dimerisation, and nuclear translocation of interferon regulatory factors (IRFs). IRFs drive a type I/III interferon response to spur cytokine production and increase the immunogenicity of the cell. Viral mimicry synergises with production and presentation of ERV-derived tumor associated antigens (green dot) via MHC-I, to increase the visibility of tumor cells for immunogenic death by cytolytic T cell activation

lines. Further, deletion of an LTR2 (a close relative of LTR2B) copy annotated as an $A P O C 1$ promoter [160], but matching an enhancer profile in immune cells [45], reduced cell proliferation and increased apoptosis. Together, these data from Deniz et al., reinforced by robust CRISPR-Cas9 based experiments, clearly depict ERVs as enhancers for genes impacting AML progression and patient survival [45]. Their results also suggest, as per normal development, that ERVs are generally more influential in AML as enhancers than as promoters, a pattern that may hold across most cancer types [43].

HERV-K Env, Rec, and Np9 proteins, as well as HERV-W Env, are detected in tumors and are proposed to have oncogenic properties [136]. Their hypothesized tumorigenicity is via routes similar to how they are co-opted in development. Akin to HERV-W Env-derived Syncytin mediation of cell fusion in the placenta, HERV-W protein upregulation in breast and endometrial cancers has been associated with increased cell-cell fusion, occurring with cancer progression, metastasis, and chemoresistance (Fig. 3b) $[5,154,155]$. There is also evidence that Env, as well as the HERV-K proviral accessory proteins, Rec and Np9, stimulate or interfere with endogenous cell signalling pathways critical for cellular growth and proliferation (Fig. 3b) [156, 161-163]. While HERV proteins are considered insufficient to induce transformation, their contribution to oncogenesis underlines their therapeutic potential [161]. Targeting HERV-K Env proteins with antibodies appears to inhibit cell growth and increase apoptosis in breast cancer cell lines, and reduce growth of xenograft tumors in mice [164, 165]. Intriguingly, regression of metastatic renal cell carcinoma was reported following allogeneic stem cell transplantation, albeit for a single patient, in which donor $\mathrm{T}$ cells recognized an HERV-E encoded antigen [166]. Thus, while ERV-mediated gene dysregulation offers a clearer path to onco-exaptation, the products of residual ERV protein-coding potential may be a more immediate and tractable therapeutic target.

\section{Therapeutic modulation of ERV expression in cancer}

Cancer therapies intended to activate ERVs have been intensely explored in recent years [56]. Despite showing promise, it remains unclear as to whether inducible ERV activity can be leveraged to treat solid tumors, especially provided potential for ERV onco-exaptation and other unintended consequences [45, 127, 143, 152]. The prevailing 
mechanistic model here, based on viral mimicry, is that TE activation can provoke an anti-tumor immune response, as described in cancer cells treated with DNA methyltransferase inhibitors (DNMTis) [101, 102, 167]. DNMTis are used as a broad-brush approach to modulate the epigenome in malignant cells and are thought to reactivate inappropriately silenced tumor suppressor genes [57]. Along with other epigenetic therapies, DNMTis have proven effective against hematological malignancies [57]. Two 2015 studies reported that DNMTi treatment stimulates ERV dsRNA production in solid tumor models, triggering an immune signalling cascade mimicking that of an exogenous virus (Fig. 3c) [101, 102]. This viral mimicry has since been achieved by inhibiting histone deacetylation complexes, lysine demethylases, and histone methyltransferases $[103,168,169]$ (Table 2) in a range of solid tumor models, including melanomas, and colorectal and ovarian cancers [101-103].

One appealing aspect of the ERV viral mimicry model is its integration with more established immune vulnerabilities exploited to treat hematological cancers [57]. In this system, ERV dsRNAs are recognized as non-self, triggering type I and type III interferon signalling. Interferon signalling can promote anti-tumor immunity through the extrinsic stimulation of cytotoxic lymphocyte populations in the tumor microenvironment, and via tumor cell intrinsic effects, including growth inhibition, modulation of apoptosis, and induction of further mediators of immune signalling [170]. While in principle the innate immune pathways stimulated by HERV products are those that are employed upon exogenous retroviral infection, further work is needed to elucidate the specific immune response to ERV induction in tumor cells. Viral mimicry in tumors has largely been inferred from type I/III interferon gene expression signatures. Consistent with an interferon response, several studies have observed infiltration of cytotoxic and helper $\mathrm{T}$ cells in the tumor microenvironment upon ERV induction in mouse models of cancer $[103,104]$. Treatment with DNMTis to induce viral mimicry enhances $\mathrm{CD}^{+} \mathrm{T}$ cell activation and detection of cytotoxic mediators in vitro $[170,171]$. ERV expression may also contribute to an adaptive immune response through the production of tumor associated neoantigens (Fig. 3c) [172]. HERVs can produce epitopes presented as MHC-I-bound peptides at the surface of tumor cells, which can increase tumor cell visibility to immune surveillance, resulting in a cytolytic T cell response [166, 173]. Crucially, enhanced immunogenicity can overcome resistance to checkpoint blockade inhibitors [57] in the treatment of solid tumors [174]. For example, CTLA-4 and PD-1 are immune checkpoint proteins that negatively regulate cytotoxic $\mathrm{T}$ cell response [175]. These molecules are upregulated in tumor cells that evade immune targeting [56]. Monoclonal antibodies against CTLA-4 and PD-1 have successfully inhibited immune checkpoint response in the clinic, enabling immune clearing of tumor cells [176, 177]. However, patient response to immune checkpoint inhibitors varies widely [178]. Promising results from melanoma mouse models suggest ERV viral mimicry brought about through inhibition of DNMT1 or the histone demethylase LSD1 can potentiate the antitumor effects of CTLA-1 and PD-1 inhibitors, respectively [101-103]. ERV-induced viral mimicry could thus prove useful in combination therapies designed to overcome resistance to immune checkpoint inhibitors, for which clinical trials are ongoing $[56,57,179]$. 
ERV demethylation and transcription as a trigger for innate immune activation is proposed to explain the clinical impact of DNMTi treatment [56, 101, 102]. While an exciting and worthwhile concept, we consider this position with some caution, and doubly so considering the clinical implications. Moving the focus away from ERVs, multiple studies have tied viral mimicry to LINEs and SINEs [167]. In colorectal cancer cells, viral mimicry has been primarily associated with inverted Alu copy dsRNAs [180], whereas in a DNMTi-treated glioblastoma cell line, SVA and ERV upregulation are comparable [181]. In hematological datasets, expression from a diverse array of TEs, including ERVs, SINEs, and LINEs, has been linked with viral mimicry upon DNMTi treatment [182]. Inactivation of the HUSH complex component MPP8 leads to both ERV and L1 upregulation, with the latter associated with dsRNA production and a type I interferon response [183]. Global ERV expression levels have been found to not predict clinical response of myelodysplasias treated with DNMTis [184]. Taken together, these results suggest that the ERV-centric model of viral mimicry upon treatment with DNMTis may be too simplistic. There is a pressing need, in our view, to move beyond inference of viral mimicry from correlations with TE family transcript levels. One approach could involve ectopic expression of various TEs upregulated in DNMTiresponsive patients, as shown to yield a gene expression signature consistent with innate immune activation [182, 183]. Arguably the most direct evidence for TE-induced viral mimicry to date comes from an RNA protection assay for MDA5 in DNMTitreated colorectal cancer cells [180]. Here, Alu, and not ERV or L1, transcripts were significantly enriched in MDA5-protected RNA, which argues that Alus are the main source of immunogenic RNA in this model [180]. Such experiments expand the viral mimicry model to include non-ERV TEs as potential therapeutic targets in cancer [167, 180, 183]. Further experiments are required to resolve the individual TE copies that are capable of inducing viral mimicry, and directly test their immunogenicity.

Advances in genome and epigenome editing, as well as sequencing technologies, provide the means to reach this level of resolution. The epigenomic analyses presented to date have tended toward a summary view of TE families. High-resolution DNA methylation and histone modification profiles for specific ERV, L1, and Alu loci with and without exposure to DNMTis would be informative, particularly if integrated with long-read transcriptomic analyses of dsRNAs and their precursor molecules. As well, long-read methylome data indicate HERV CpG methylation is already lower than that of other TEs and the remaining genome in normal tissues, and may be less reduced in tumor cells [79]. It is therefore possible that in many tumor cells DNA methylation may not be the predominant mechanism employed to limit ERV transcription [125]. Histone deacetylase inhibitors and lysine methyltransferase inhibitors strongly synergise with DNMTis to activate ERVs $[42,106]$, while repressive chromatin pathways can have compensatory effects $[105,119,125,185,186]$. These considerations are likely to impact the success of ERV-focused cancer therapeutics.

Given recent evidence implicating a number of TE families in triggering viral mimicry, it would now be beneficial to directly dissect and modulate ERV activity in preclinical tumor models. A challenge in targeting ERVs, and TEs in general, is specificity; most studies of ERV function in cancer have examined entire ERV families, whereas few have targeted specific loci [45, 101-103]. Data obtained from cancer cell lines have shown that in vitro-transcribed ERVs can trigger gene expression changes that indicate 
viral mimicry, and that different ERVs evoke different gene expression signatures [182]. This highlights the need to dissect ERV families and individual ERV loci in mechanistic explanations founded on viral mimicry. To be more clinically relevant, these studies could be expanded to study the modulation of ERVs and other endogenous TEs in situ via CRISPR-Cas9 and CRISPR-dCas9 strategies [45]. As CRISPR-Cas9 genome editing relies upon guide RNA (gRNA) identity to specific target sequences, and ERVs form families of closely related sequences, it is possible to CRISPR-Cas9 edit entire ERV families, as well as individual ERV loci [10, 12, 16, 45, 92]. In addition to providing a deeper and more precise understanding of ERV loci that could be immunogenic, this approach could indicate more examples involved in onco-exaptation, such as the APOC1 LTR2 enhancer highlighted by Deniz et al. [45]. CRISPR-dCas9 fusion proteins can also be employed to bring activating (CRISPRa) and interfering repressor (CRISPRi) complexes to specific TE loci. This approach has proven particularly useful for ERVs, where activator (e.g., CRISPR-dCas9-VPR) and repressor (e.g., CRISPR-dCas9-KRAB) fusion proteins can be used to assess the downstream effects of modulating ERV activity [10, 12, $45,92,93]$. In the context of cancer, the downstream consequences for dsRNA production and interferon signalling upon ERV activation could then be assessed. Even if various obstacles to their application to cancer still need to be addressed, the use of CRIS PR-Cas9 tools will greatly facilitate hypothesis testing surrounding ERV regulation and function, particularly in instances inferred from epigenome data and correlated transcription $[2,20,21,43,91]$.

Preclinical modulation of ERV expression has been pursued with agents that induce global changes to the cancer epigenome landscape (Table 2). Although many of these therapies are FDA approved for hematological malignancies, their utility against solid tumors is less established. Their lack of precision and selectivity are potential drawbacks, as epigenetic modifiers are ubiquitously expressed and of multifaceted function. Epigenetic therapies thus present a challenge to elucidate the mechanism(s) linking a given inhibitor with altered tumor cell phenotype. With this complexity in mind, it is perhaps unsurprising that the main upstream effectors of the viral mimicry pathway remain to be resolved with certainty [180]. The clinical success of epigenetic therapies rests on the greater dependence of tumor cells on the targeted chromatin modifiers to drive aberrant transcriptional programs, compared to homeostatic transcription in normal cells [57]. Specific ERV reactivation leading to an immune response is arguably a more exact objective, and one perhaps more easily reached via another strategy. For example, KAP1 deletion has a more pronounced effect on the expression of ERVs than on protein-coding genes [18]. In mouse models of melanoma, KAP1 knockout enhances ERV-mediated viral mimicry [187]. Developmental ERV expression occurs in windows of epigenetic reprogramming and is facilitated by transactivator binding [7, 9, $16,46,47,81-83,93]$. Identification of ERV transactivators that are expressed in cancer, but not normal cells, could provide a therapeutic avenue to stimulate ERV expression with sufficient specificity to exclude other genomic elements. One caveat of this approach is that modulation of developmental ERV transactivators alone may not be immunogenic, as apparent for DUX4 [188]. Other barriers to the use of more precise epigenetic therapies against ERVs, perhaps involving CRISPR-dCas9 fusion proteins, are delivery and safety, which have been overcome for many FDA-approved DNMTis. A higher-resolution view of the chromatin and cell signalling pathways that converge 
to activate ERV expression in development and disease will likely illuminate new therapeutic targets.

\section{Future directions}

Cancer, inflammation, and embryogenesis all bear witness to the impact of ERVs on human biology. Here we have attempted to bring forward exemplary studies that resolve and explain how ERV-derived nucleic acid and protein function in these contexts. The bulk of such phenomena are partially described, or fully remain to be uncovered. It is apparent that ERVs are expressed in a range of malignancies, including in response to therapeutic agents, and may serve as prognostic biomarkers [156, 189]. While the functions or mechanisms by which ERVs can contribute to pathology are frequently not well understood, new strategies focused on ERVs to treat common and deadly diseases hold obvious merit. To our knowledge, ERV modulation in preclinical studies of cancer, as well as of autoimmune and neurodegenerative conditions, has been approached globally, such as with epigenetic therapies or reverse transcriptase inhibitors. More precise, and higher-resolution, approaches illuminated by a deeper understanding of ERV regulation in somatic cells could accelerate development of ERV-focused therapeutics. Fortunately, long-read sequencing and CRISPR-Cas9 technologies have emerged as powerful tools to probe the causal contributions made by ERVs to pathology. While the role of ERVs, and other TEs [149, 180], in generating viral mimicry and inducible interferon responses in cancer are clearly an area of priority, similar experimental techniques could be applied to autoimmune and neurodegenerative diseases where ERV dysregulation is encountered. A comprehensive view of ERV regulation and function in normal cells, combined with the specific contributions made by ERVs to disease, is required to fully realize their exciting if still preliminary clinical potential.

\section{Supplementary Information}

The online version contains supplementary material available at https://doi.org/10.1186/s13059-021-02357-4.

Additional file 1. Review history.

\section{Acknowledgements}

The authors apologize for instances of relevant studies from our peers that could not be cited due to space constraints. We thank Dixie Mager, Patricia Carreira, Patricia Gerdes, Nathan Smits, and members of the Faulkner laboratory for helpful discussions. NJ was supported by an Australian NHMRC Investigator Grant (GNT1176574). GJF received funding from a CSL Centenary Fellowship, an NHMRC Investigator Grant (GNT1173711), and the Mater Foundation.

Review history

The review history is available as Additional file 1.

Peer review information

Anahita Bishop was the primary editor of this article and managed its editorial process and peer review in collaboration with the rest of the editorial team.

Authors' contributions

NJ and GJF planned the review, read the literature, and drafted the text. NJ constructed Fig. 3 and Table 2. GJF assembled Fig. 1, Fig. 2, and Table 1. Both authors approved the final manuscript.

\section{Declarations}




\title{
Author details
}

${ }^{1}$ Mater Research Institute - University of Queensland, TRI Building, Woolloongabba, QLD 4102, Australia. ${ }^{2}$ Queensland Brain Institute, University of Queensland, Brisbane, QLD 4072, Australia.

\section{Received: 17 February 2021 Accepted: 21 April 2021}

\author{
Published online: 10 May 2021
}

\section{References}

1. Lander ES, Linton LM, Birren B, Nusbaum C, Zody MC, Baldwin J, et al. Initial sequencing and analysis of the human genome. Nature. 2001:409:860-921.

2. ENCODE Project Consortium, Moore JE, Purcaro MJ, Pratt HE, Epstein CB, Shoresh N, et al. Expanded encyclopaedias of DNA elements in the human and mouse genomes. Nature. 2020;583:699-710.

3. Bannert N, Kurth R. The evolutionary dynamics of human endogenous retroviral families. Annu Rev Genomics Hum Genet. 2006;7:149-73.

4. Mager DL, Stoye JP. Mammalian endogenous retroviruses. Microbiol Spectr. 2015;3:1-20.

5. Mi S, Lee X, Li X, Veldman GM, Finnerty H, Racie L, et al. Syncytin is a captive retroviral envelope protein involved in human placental morphogenesis. Nature. 2000;403:785-9.

6. Pastuzyn ED, Day CE, Kearns RB, Kyrke-Smith M, Taibi AV, McCormick J, et al. The neuronal gene arc encodes a repurposed retrotransposon gag protein that mediates intercellular RNA transfer. Cell. 2018;173:275.

7. Lu X, Sachs F, Ramsay L, Jacques P-É, Göke J, Bourque G, et al. The retrovirus HERVH is a long noncoding RNA required for human embryonic stem cell identity. Nat Struct Mol Biol. 2014;21:423-5.

8. Durruthy-Durruthy J, Sebastiano V, Wossidlo M, Cepeda D, Cui J, Grow EJ, et al. The primate-specific noncoding RNA HPAT5 regulates pluripotency during human preimplantation development and nuclear reprogramming. Nat Genet. 2016:48:44-52.

9. Grow EJ, Flynn RA, Chavez SL, Bayless NL, Wossidlo M, Wesche DJ, et al. Intrinsic retroviral reactivation in human preimplantation embryos and pluripotent cells. Nature. 2015;522:221-5.

10. Fuentes DR, Swigut T, Wysocka J. Systematic perturbation of retroviral LTRs reveals widespread long-range effects on human gene regulation. Elife. 2018;7:e35989.

11. Wang J, Xie G, Singh M, Ghanbarian AT, Raskó T, Szvetnik A, et al. Primate-specific endogenous retrovirus-driven transcription defines naive-like stem cells. Nature. 2014;516:405-9.

12. Zhang Y, Li T, Preiss S S, Amaral ML, Grinstein JD, Farah EN, et al. Transcriptionally active HERV-H retrotransposons demarcate topologically associating domains in human pluripotent stem cells. Nat Genet. 2019;51:1380-8.

13. Chuong EB, Rumi MAK, Soares MJ, Baker JC. Endogenous retroviruses function as species-specific enhancer elements in the placenta. Nat Genet. 2013;45:325-9.

14. Dunn-Fletcher CE, Muglia LM, Pavlicev M, Wolf G, Sun M-A, Hu Y-C, et al. Anthropoid primate-specific retroviral element THE1B controls expression of CRH in placenta and alters gestation length. Plos Biol. 2018;16:e2006337.

15. van de Lagemaat LN, Landry J-R, Mager DL, Medstrand P. Transposable elements in mammals promote regulatory variation and diversification of genes with specialized functions. Trends Genet. 2003;19:530-6.

16. Chuong EB, Elde NC, Feschotte C. Regulatory evolution of innate immunity through co-option of endogenous retroviruses. Science. 2016;351:1083-7.

17. Ye M, Goudot C, Hoyler T, Lemoine B, Amigorena S, Zueva E. Specific subfamilies of transposable elements contribute to different domains of T lymphocyte enhancers. Proc Natl Acad Sci U S A. 2020;117:7905-16.

18. Tie CH, Fernandes $L$, Conde L, Robbez-Masson L, Sumner RP, Peacock T, et al. KAP1 regulates endogenous retroviruses in adult human cells and contributes to innate immune control. EMBO Rep. 2018;19:e45000.

19. Chuong EB, Elde NC, Feschotte C. Regulatory activities of transposable elements: from conflicts to benefits. Nat Rev Genet. 2017;18:71-86.

20. Jacques P-É, Jeyakani J, Bourque G. The majority of primate-specific regulatory sequences are derived from transposable elements. Plos Genet. 2013;9:e1003504.

21. Faulkner GJ, Kimura Y, Daub CO, Wani S, Plessy C, Irvine KM, et al. The regulated retrotransposon transcriptome of mammalian cells. Nat Genet. 2009:41:563-71.

22. Turelli P, Playfoot C, Grun D, Raclot C, Pontis J, Coudray A, et al. Primate-restricted KRAB zinc finger proteins and target retrotransposons control gene expression in human neurons. Sci Adv. 2020;6:eaba3200.

23. Romanish MT, Lock WM, van de Lagemaat LN, Dunn CA, Mager DL. Repeated recruitment of LTR retrotransposons as promoters by the anti-apoptotic locus NAIP during mammalian evolution. Plos Genet. 2007;3:e10

24. Thompson PJ, Macfarlan TS, Lorincz MC. Long terminal repeats: from parasitic elements to building blocks of the transcriptional regulatory repertoire. Mol Cell. 2016;62:766-76.

25. Notwell JH, Chung T, Heavner W, Bejerano G. A family of transposable elements co-opted into developmental enhancers in the mouse neocortex. Nat Commun. 2015;6:6644.

26. Cohen CJ, Lock WM, Mager DL. Endogenous retroviral LTRs as promoters for human genes: a critical assessment. Gene. 2009:448:105-14

27. Ward MC, Wilson MD, Barbosa-Morais NL, Schmidt D, Stark R, Pan Q, et al. Latent regulatory potential of human-specific repetitive elements. Mol Cell. 2013;49:262-72.

28. Kazazian HH Jr, Moran JV. Mobile DNA in health and disease. N Engl J Med. 2017;377:361-70.

29. Denli AM, Narvaiza I, Kerman BE, Pena M, Benner C, Marchetto MCN, et al. Primate-specific ORFO contributes to retrotransposon-mediated diversity. Cell. 2015;163:583-93.

30. Subramanian RP, Wildschutte JH, Russo C, Coffin JM. Identification, characterization, and comparative genomic distribution of the HERV-K (HML-2) group of human endogenous retroviruses. Retrovirology. 2011;8:90.

31. Thomas J, Perron H, Feschotte C. Variation in proviral content among human genomes mediated by LTR recombination. Mob DNA. 2018;9:36.

32. Pavlícek A, Paces J, Elleder D, Hejnar J. Processed pseudogenes of human endogenous retroviruses generated by LINEs: their integration, stability, and distribution. Genome Res. 2002;12:391-9. 
33. Gerdes P, Richardson SR, Mager DL, Faulkner GJ. Transposable elements in the mammalian embryo: pioneers surviving through stealth and service. Genome Biol. 2016;17:100.

34. Mager DL, Henthorn PS. Identification of a retrovirus-like repetitive element in human DNA. Proc Natl Acad Sci U S A. 1984;81:7510-4.

35. Turner G, Barbulescu M, Su M, Jensen-Seaman Ml, Kidd KK, Lenz J. Insertional polymorphisms of full-length endogenous retroviruses in humans. Curr Biol. 2001:11:1531-5.

36. Medstrand P, Mager DL. Human-specific integrations of the HERV-K endogenous retrovirus family. J Virol. 1998;72:9782-7.

37. Wildschutte JH, Williams ZH, Montesion M, Subramanian RP, Kidd JM, Coffin JM. Discovery of unfixed endogenous retrovirus insertions in diverse human populations. Proc Natl Acad Sci U S A. 2016;113:E2326-34.

38. Marchi E, Kanapin A, Magiorkinis G, Belshaw R. Unfixed endogenous retroviral insertions in the human population. J Virol. 2014;88:9529-37.

39. Macfarlane CM, Badge RM. Genome-wide amplification of proviral sequences reveals new polymorphic HERV-K(HML-2) proviruses in humans and chimpanzees that are absent from genome assemblies. Retrovirology. 2015;12:35.

40. Li W, Lin L, Malhotra R, Yang L, Acharya R, Poss M. A computational framework to assess genome-wide distribution of polymorphic human endogenous retrovirus-K In human populations. Plos Comput Biol. 2019;15:e1006564.

41. Hughes JF, Coffin JM. Human endogenous retrovirus K solo-LTR formation and insertional polymorphisms: implications for human and viral evolution. Proc Natl Acad Sci U S A. 2004;101:1668-72.

42. Brocks D, Schmidt CR, Daskalakis M, Jang HS, Shah NM, Li D, et al. DNMT and HDAC inhibitors induce cryptic transcription start sites encoded in long terminal repeats. Nat Genet. 2017;49:1052-60.

43. Jang HS, Shah NM, Du AY, Dailey ZZ, Pehrsson EC, Godoy PM, et al. Transposable elements drive widespread expression of oncogenes in human cancers. Nat Genet. 2019;51:611-7.

44. Fort A, Hashimoto K, Yamada D, Salimullah M, Keya CA, Saxena A, et al. Deep transcriptome profiling of mammalian stem cells supports a regulatory role for retrotransposons in pluripotency maintenance. Nat Genet. 2014;46:558-66.

45. Deniz Ö, Ahmed M, Todd CD, Rio-Machin A, Dawson MA, Branco MR. Endogenous retroviruses are a source of enhancers with oncogenic potential in acute myeloid leukaemia. Nat Commun. 2020;11:3506.

46. Bourque $\mathrm{G}$, Leong $\mathrm{B}$, Vega $\mathrm{VB}$, Chen $\mathrm{X}$, Lee YL, Srinivasan KG, et al. Evolution of the mammalian transcription factor binding repertoire via transposable elements. Genome Res. 2008;18:1752-62.

47. Hermant C, Torres-Padilla M-E. TFs for TEs: the transcription factor repertoire of mammalian transposable elements, Genes Dev. 2021;35:22-39.

48. Wang J, Zhuang J, lyer S, Lin X, Whitfield TW, Greven MC, et al. Sequence features and chromatin structure around the genomic regions bound by 119 human transcription factors. Genome Res. 2012;22:1798-812.

49. Wolf G, Yang P, Füchtbauer AC, Füchtbauer E-M, Silva AM, Park C, et al. The KRAB zinc finger protein ZFP809 is required to initiate epigenetic silencing of endogenous retroviruses. Genes Dev. 2015;29:538-54.

50. Ohtani H, Liu M, Zhou W, Liang G, Jones PA. Switching roles for DNA and histone methylation depend on evolutionary ages of human endogenous retroviruses. Genome Res. 2018;28:1147-57.

51. Deniz Ö, Frost JM, Branco MR. Regulation of transposable elements by DNA modifications. Nat Rev Genet. 2019;20:417-31.

52. Rowe HM, Jakobsson J, Mesnard D, Rougemont J, Reynard S, Aktas T, et al. KAP1 controls endogenous retroviruses in embryonic stem cells. Nature. 2010;463:237-40.

53. Ecco G, Cassano M, Kauzlaric A, Duc J, Coluccio A, Offner S, et al. Transposable elements and their KRAB-ZFP controllers regulate gene expression in adult tissues. Dev Cell. 2016;36:611-23.

54. Imbeault M, Helleboid P-Y, Trono D. KRAB zinc-finger proteins contribute to the evolution of gene regulatory networks. Nature. 2017;543:550-4

55. Cosby RL, Chang N-C, Feschotte C. Host-transposon interactions: conflict, cooperation, and cooption. Genes Dev. 2019; 33:1098-116.

56. Jones PA, Ohtani H, Chakravarthy A, De Carvalho DD. Epigenetic therapy in immune-oncology. Nat Rev Cancer. 2019;19: 151-61.

57. Dawson MA. The cancer epigenome: Concepts, challenges, and therapeutic opportunities. Science. 2017;355:1147-52.

58. Löwer R, Löwer J, Kurth R. The viruses in all of us: characteristics and biological significance of human endogenous retrovirus sequences. Proc Natl Acad Sci U S A. 1996;93:5177-84.

59. Jern P, Sperber GO, Blomberg J. Definition and variation of human endogenous retrovirus H. Virology. 2004;327:93-110.

60. Dewannieux M, Harper F, Richaud A, Letzelter C, Ribet D, Pierron G, et al. Identification of an infectious progenitor for the multiple-copy HERV-K human endogenous retroelements. Genome Res. 2006;16:1548-56.

61. Dewannieux M, Blaise $S$, Heidmann T. Identification of a functional envelope protein from the HERV-K family of human endogenous retroviruses. J Virol. 2005;79:15573-7.

62. Tarlinton RE, Meers J, Young PR. Retroviral invasion of the koala genome. Nature. 2006;442:79-81.

63. Dewannieux M, Dupressoir A, Harper F, Pierron G, Heidmann T. Identification of autonomous IAP LTR retrotransposons mobile in mammalian cells. Nat Genet. 2004;36:534-9.

64. Lee YN, Bieniasz PD. Reconstitution of an infectious human endogenous retrovirus. PLoS Pathog. 2007;3:e10.

65. Brady T, Lee YN, Ronen K, Malani N, Berry CC, Bieniasz PD, et al. Integration target site selection by a resurrected human endogenous retrovirus. Genes Dev. 2009;23:633-42.

66. Fuchs NV, Loewer S, Daley GQ, Izsvák Z, Löwer J, Löwer R. Human endogenous retrovirus K (HML-2) RNA and protein expression is a marker for human embryonic and induced pluripotent stem cells. Retrovirology. 2013;10:115.

67. Klawitter S, Fuchs NV, Upton KR, Muñoz-Lopez M, Shukla R, Wang J, et al. Reprogramming triggers endogenous L1 and Alu retrotransposition in human induced pluripotent stem cells. Nat Commun. 2016;7:10286.

68. Khan H, Smit A, Boissinot S. Molecular evolution and tempo of amplification of human LINE-1 retrotransposons since the origin of primates. Genome Res. 2006;16:78-87.

69. Salvador-Palomeque C, Sanchez-Luque FJ, Fortuna PRJ, Ewing AD, Wolvetang EJ, Richardson SR, et al. Dynamic methylation of an L1 transduction family during reprogramming and neurodifferentiation. Mol Cell Biol. 2019:39:e00499.

70. Schön U, Diem O, Leitner L, Günzburg WH, Mager DL, Salmons B, et al. Human endogenous retroviral long terminal repeat sequences as cell type-specific promoters in retroviral vectors. J Virol. 2009;83:12643-50. 
71. Speek M. Antisense promoter of human L1 retrotransposon drives transcription of adjacent cellular genes. Mol Cell Biol. 2001;21:1973-85.

72. Kovalskaya E, Buzdin A, Gogvadze E, Vinogradova T, Sverdlov E. Functional human endogenous retroviral LTR transcription start sites are located between the R and U5 regions. Virology. 2006;346:373-8.

73. Medstrand P, van de Lagemaat LN, Mager DL. Retroelement distributions in the human genome: variations associated with age and proximity to genes. Genome Res. 2002;12:1483-95.

74. Swergold GD. Identification, characterization, and cell specificity of a human LINE-1 promoter. Mol Cell Biol. 1990;10: 6718-29.

75. Sultana T, van Essen D, Siol O, Bailly-Bechet M, Philippe C, Zine El Aabidine A, et al. The landscape of L1 retrotransposons in the human genome is shaped by pre-insertion sequence biases and post-insertion selection. Mol Cell. 2019;74:555-70

76. Goodier JL. Restricting retrotransposons: a review. Mob DNA. 2016;7:16.

77. Mager DL, Goodchild NL. Homologous recombination between the LTRs of a human retrovirus-like element causes a 5kb deletion in two siblings. Am J Hum Genet. 1989;45:848-54.

78. Rebollo R, Miceli-Royer K, Zhang Y, Farivar S, Gagnier L, Mager DL. Epigenetic interplay between mouse endogenous retroviruses and host genes. Genome Biol. 2012;13:R89.

79. Ewing AD, Smits N, Sanchez-Luque FJ, Faivre J, Brennan PM, Richardson SR, et al. Nanopore sequencing enables comprehensive transposable element epigenomic profiling. Mol Cell. 2020;80:915-28.

80. Zhou W, Emery SB, Flasch DA, Wang Y, Kwan KY, Kidd JM, et al. Identification and characterization of occult humanspecific LINE-1 insertions using long-read sequencing technology. Nucleic Acids Res. 2020;48:1146-63.

81. Trizzino M, Park Y, Holsbach-Beltrame M, Aracena K, Mika K, Caliskan M, et al. Transposable elements are the primary source of novelty in primate gene regulation. Genome Res. 2017;27:1623-33.

82. Kunarso G, Chia N-Y, Jeyakani J, Hwang C, Lu X, Chan Y-S, et al. Transposable elements have rewired the core regulatory network of human embryonic stem cells. Nat Genet. 2010;42:631-4.

83. Göke J, Lu X, Chan Y-S, Ng H-H, Ly L-H, Sachs F, et al. Dynamic transcription of distinct classes of endogenous retroviral elements marks specific populations of early human embryonic cells. Cell Stem Cell. 2015;16:135-41.

84. Hendrickson PG, Doráis JA, Grow EJ, Whiddon JL, Lim J-W, Wike CL, et al. Conserved roles of mouse DUX and human DUX4 in activating cleavage-stage genes and MERVL/HERVL retrotransposons. Nat Genet. 2017:49:925-34.

85. Bénit L, Lallemand JB, Casella JF, Philippe H, Heidmann T. ERV-L elements: a family of endogenous retrovirus-like elements active throughout the evolution of mammals. J Virol. 1999;73:3301-8.

86. Peaston AE, Evsikov AV, Graber JH, de Vries WN, Holbrook AE, Solter D, et al. Retrotransposons regulate host genes in mouse oocytes and preimplantation embryos. Dev Cell. 2004;7:597-606.

87. Macfarlan TS, Gifford WD, Driscoll S, Lettieri K, Rowe HM, Bonanomi D, et al. Embryonic stem cell potency fluctuates with endogenous retrovirus activity. Nature. 2012;487:57-63.

88. Yang F, Huang X, Zang R, Chen J, Fidalgo M, Sanchez-Priego C, et al. DUX-miR-344-ZMYM2-mediated activation of MERVL LTRs induces a totipotent 2C-like state. Cell Stem Cell. 2020;26:234-50.

89. Wang Y, Xu Z, Jiang J, Xu C, Kang J, Xiao L, et al. Endogenous miRNA sponge lincRNA-RoR regulates Oct4, Nanog, and Sox2 in human embryonic stem cell self-renewal. Dev Cell. 2013;25:69-80.

90. Kelley D, Rinn J. Transposable elements reveal a stem cell-specific class of long noncoding RNAs. Genome Biol. 2012;13:R107.

91. FANTOM Consortium and the RIKEN PMI and CLST (DGT), Forrest ARR, Kawaji H, Rehli M, Baillie JK, MJL d H, et al. A promoter-level mammalian expression atlas. Nature. 2014;507:462-70.

92. Todd CD, Deniz Ö, Taylor D, Branco MR. Functional evaluation of transposable elements as enhancers in mouse embryonic and trophoblast stem cells. Elife. 2019;8:e44344.

93. Pontis J, Planet E, Offner S, Turelli P, Duc J, Coudray A, et al. Hominoid-specific transposable elements and KZFPs facilitate human embryonic genome activation and control transcription in naive human ESCs. Cell Stem Cell. 2019;24: 724-35.

94. Ito J, Sugimoto R, Nakaoka H, Yamada S, Kimura T, Hayano T, et al. Systematic identification and characterization of regulatory elements derived from human endogenous retroviruses. Plos Genet. 2017;13:e1006883.

95. Manghera M, Ferguson-Parry J, Lin R, Douville RN. NF-KB and IRF1 induce endogenous retrovirus K expression via interferon-stimulated response elements in its 5' long terminal repeat. J Virol. 2016;90:9338-49.

96. Schmid CD, Bucher P. MER41 repeat sequences contain inducible STAT1 binding sites. Plos One. 2010;5:e11425.

97. Hornung V, Ablasser A, Charrel-Dennis M, Bauernfeind F, Horvath G, Caffrey DR, et al. AlM2 recognizes cytosolic dsDNA and forms a caspase-1-activating inflammasome with ASC. Nature. 2009;458:514-8.

98. Raviram R, Rocha PP, Luo VM, Swanzey E, Miraldi ER, Chuong EB, et al. Analysis of 3D genomic interactions identifies candidate host genes that transposable elements potentially regulate. Genome Biol. 2018;19:216.

99. Greenberg MVC, Bourc'his D. The diverse roles of DNA methylation in mammalian development and disease. Nat Rev Mol Cell Biol. 2019;20:590-607.

100. Ecco G, Imbeault M, Trono D. KRAB zinc finger proteins. Development. 2017;144:2719-29.

101. Roulois D, Loo Yau H, Singhania R, Wang Y, Danesh A, Shen SY, et al. DNA-demethylating agents target colorectal cancer cells by inducing viral mimicry by endogenous transcripts. Cell. 2015;162:961-73.

102. Chiappinelli KB, Strissel PL, Desrichard A, Li H, Henke C, Akman B, et al. Inhibiting DNA methylation causes an interferon response in cancer via dsRNA including endogenous retroviruses. Cell. 2016;164:1073.

103. Sheng W, LaFleur MW, Nguyen TH, Chen S, Chakravarthy A, Conway JR, et al. LSD1 ablation stimulates anti-tumor immunity and enables checkpoint blockade. Cell. 2018;174:549-63.

104. Cañadas I, Thummalapalli R, Kim JW, Kitajima S, Jenkins RW, Christensen CL, et al. Tumor innate immunity primed by specific interferon-stimulated endogenous retroviruses. Nat Med. 2018;24:1143-50.

105. Deblois G, Tonekaboni SAM, Grillo G, Martinez C, Kao Yl, Tai F, et al. Epigenetic switch-induced viral mimicry evasion in chemotherapy-resistant breast cancer. Cancer Discov. 2020;10:1312-29.

106. Liu M, Thomas SL, DeWitt AK, Zhou W, Madaj ZB, Ohtani H, et al. Dual inhibition of DNA and histone methyltransferases increases viral mimicry in ovarian cancer cells. Cancer Res. 2018;78:5754-66. 
107. Zhang H, Pandey S, Travers M, Sun H, Morton G, Madzo J, et al. Targeting CDK9 reactivates epigenetically silenced genes in cancer. Cell. 2018;175:1244-58.

108. Goel S, DeCristo MJ, Watt AC, BrinJones H, Sceneay J, Li BB, et al. CDK4/6 inhibition triggers anti-tumour immunity. Nature. 2017;548:471-5.

109. Liu M, Ohtani H, Zhou W, Ørskov AD, Charlet J, Zhang YW, et al. Vitamin C increases viral mimicry induced by 5-aza-2'deoxycytidine. Proc Natl Acad Sci U S A. 2016;113:10238-44.

110. Zhao H, Ning S, Nolley R, Scicinski J, Oronsky B, Knox SJ, et al. The immunomodulatory anticancer agent, RRx-001, induces an interferon response through epigenetic induction of viral mimicry. Clin Epigenetics. 2017:9:4.

111. Chelmicki T, Roger E, Teissandier A, Dura M, Bonneville L, Rucli S, et al. m6A RNA methylation regulates the fate of endogenous retroviruses. Nature. 2021;591:312-6.

112. Zoch A, Auchynnikava T, Berrens RV, Kabayama Y, Schöpp T, Heep M, et al. SPOCD1 is an essential executor of piRNAdirected de novo DNA methylation. Nature. 2020;584:635-9.

113. Kuramochi-Miyagawa S, Watanabe T, Gotoh K, Totoki Y, Toyoda A, Ikawa M, et al. DNA methylation of retrotransposon genes is regulated by Piwi family members MILI and MIVI2 in murine fetal testes. Genes Dev. 2008;22:908-17.

114. Aravin AA, Sachidanandam R, Girard A, Fejes-Toth K, Hannon GJ. Developmentally regulated piRNA clusters implicate MILI in transposon control. Science. 2007;316:744-7.

115. Bourc'his D, Bestor TH. Meiotic catastrophe and retrotransposon reactivation in male germ cells lacking Dnmt3L. Nature. 2004;431:96-9.

116. Tosar JP, Rovira C, Cayota A. Non-coding RNA fragments account for the majority of annotated piRNAs expressed in somatic non-gonadal tissues. Communications Biology. 2018;1:2.

117. Jacobs FMJ, Greenberg D, Nguyen N, Haeussler M, Ewing AD, Katzman S, et al. An evolutionary arms race between KRAB zinc-finger genes ZNF91/93 and SVA/L1 retrotransposons. Nature. 2014;516:242-5.

118. Yan L, Yang M, Guo H, Yang L, Wu J, Li R, et al. Single-cell RNA-Seq profiling of human preimplantation embryos and embryonic stem cells. Nat Struct Mol Biol. 2013;20:1131-9.

119. Turelli P, Castro-Diaz N, Marzetta F, Kapopoulou A, Raclot C, Duc J, et al. Interplay of TRIM28 and DNA methylation in controlling human endogenous retroelements. Genome Res. 2014;24:1260-70.

120. Najafabadi HS, Mnaimneh S, Schmitges FW, Garton M, Lam KN, Yang A, et al. C2H2 zinc finger proteins greatly expand the human regulatory lexicon. Nat Biotechnol. 2015;33:555-62

121. Rowe HM, Friedli M, Offner S, Verp S, Mesnard D, Marquis J, et al. De novo DNA methylation of endogenous retroviruses is shaped by KRAB-ZFPs/KAP1 and ESET. Development. 2013;140:519-29.

122. Quenneville S, Turelli P, Bojkowska K, Raclot C, Offner S, Kapopoulou A, et al. The KRAB-ZFP/KAP1 system contributes to the early embryonic establishment of site-specific DNA methylation patterns maintained during development. Cell Rep. 2012;2:766-73.

123. Schultz DC, Ayyanathan K, Negorev D, Maul GG, Rauscher FJ 3rd. SETDB1: a novel KAP-1-associated histone H3, lysine 9specific methyltransferase that contributes to HP1-mediated silencing of euchromatic genes by KRAB zinc-finger proteins. Genes Dev. 2002;16:919-32.

124. Deniz Ö, de la Rica L, Cheng KCL, Spensberger D, Branco MR. SETDB1 prevents TET2-dependent activation of IAP retroelements in naïve embryonic stem cells. Genome Biol. 2018;19:6.

125. López-Moyado IF, Tsagaratou A, Yuita H, Seo H, Delatte B, Heinz S, et al. Paradoxical association of TET loss of function with genome-wide DNA hypomethylation. Proc Natl Acad Sci U S A. 2019;116:16933-42.

126. Pehrsson EC, Choudhary MNK, Sundaram V, Wang T. The epigenomic landscape of transposable elements across normal human development and anatomy. Nat Commun. 2019;10:1-16.

127. Babaian A, Mager DL. Endogenous retroviral promoter exaptation in human cancer. Mob DNA. 2016;7:24.

128. Nowick K, Hamilton AT, Zhang H, Stubbs L. Rapid sequence and expression divergence suggest selection for novel function in primate-specific KRAB-ZNF genes. Mol Biol Evol. 2010;27:2606-17.

129. Leung A, Trac C, Kato H, Costello KR, Chen Z, Natarajan R, et al. LTRs activated by Epstein-Barr virus-induced transformation of B cells alter the transcriptome. Genome Res. 2018;28:1791-8.

130. Stehelin D, Varmus HE, Bishop JM, Vogt PK. DNA related to the transforming gene(s) of avian sarcoma viruses is present in normal avian DNA. Nature. 1976;260:170-3.

131. Sung W-K, Zheng H, Li S, Chen R, Liu X, Li Y, et al. Genome-wide survey of recurrent HBV integration in hepatocellular carcinoma. Nat Genet. 2012;44:765-9.

132. Schauer SN, Carreira PE, Shukla R, Gerhardt DJ, Gerdes P, Sanchez-Luque FJ, et al. L1 retrotransposition is a common feature of mammalian hepatocarcinogenesis. Genome Res. 2018;28:639-53.

133. Shukla R, Upton KR, Muñoz-Lopez M, Gerhardt DJ, Fisher ME, Nguyen T, et al. Endogenous retrotransposition activates oncogenic pathways in hepatocellular carcinoma. Cell. 2013;153:101-11.

134. Kassiotis G, Stoye JP. Immune responses to endogenous retroelements: taking the bad with the good. Nat Rev Immunol. 2016;16:207-19.

135. Dubnau J. The Retrotransposon storm and the dangers of a Collyer's genome. Curr Opin Genet Dev. 2018;49:95-105.

136. Grandi N, Tramontano E. HERV envelope proteins: physiological role and pathogenic potential in cancer and autoimmunity. Front Microbiol. 2018;9:462.

137. Tam OH, Ostrow LW, Gale HM. Diseases of the nERVous system: retrotransposon activity in neurodegenerative disease. Mob DNA. 2019;10:32.

138. Young GR, Eksmond U, Salcedo R, Alexopoulou L, Stoye JP, Kassiotis G. Resurrection of endogenous retroviruses in antibody-deficient mice. Nature. 2012;491:774-8.

139. Rolland A, Jouvin-Marche E, Viret C, Faure M, Perron H, Marche PN. The envelope protein of a human endogenous retrovirus-W family activates innate immunity through CD14/TLR4 and promotes Th1-like responses. J Immunol. 2006; 176:7636-44.

140. Yu P, Lübben W, Slomka H, Gebler J, Konert M, Cai C, et al. Nucleic acid-sensing Toll-like receptors are essential for the control of endogenous retrovirus viremia and ERV-induced tumors. Immunity. 2012;37:867-79.

141. Chow J, Franz KM, Kagan JC. PRRs are watching you: Localization of innate sensing and signaling regulators. Virology. 2015;479-480:104-9. 
142. Hartmann G. Nucleic Acid Immunity. Adv Immunol. 2017;133:121-69.

143. Lamprecht B, Walter K, Kreher S, Kumar R, Hummel M, Lenze D, et al. Derepression of an endogenous long terminal repeat activates the CSF1R proto-oncogene in human lymphoma. Nat Med. 2010;16:571-9.

144. Lynch-Sutherland CF, Chatterjee A, Stockwell PA, Eccles MR, Macaulay EC. Reawakening the developmental origins of cancer through transposable elements. Front Oncol. 2020;10:468.

145. Scott EC, Gardner EJ, Masood A, Chuang NT, Vertino PM, Devine SE. A hot L1 retrotransposon evades somatic repression and initiates human colorectal cancer. Genome Res. 2016;26:745-55.

146. Morrish TA, Gilbert N, Myers JS, Vincent BJ, Stamato TD, Taccioli GE, et al. DNA repair mediated by endonucleaseindependent LINE-1 retrotransposition. Nat Genet. 2002;31:159-65.

147. Scott EC, Devine SE. The role of somatic L1 retrotransposition in human cancers. Viruses. 2017;9:131.

148. Rodriguez-Martin B, Alvarez EG, Baez-Ortega A, Zamora J, Supek F, Demeulemeester J, et al. Pan-cancer analysis of whole genomes identifies driver rearrangements promoted by LINE-1 retrotransposition. Nat Genet. 2020;52:306-19.

149. Ardeljan D, Steranka JP, Liu C, Li Z, Taylor MS, Payer LM, et al. Cell fitness screens reveal a conflict between LINE-1 retrotransposition and DNA replication. Nat Struct Mol Biol. 2020;27:168-78.

150. Doucet-O'Hare T, Rodić N, Sharma R, Darbari I, Abril G, Choi JA, et al. LINE-1 expression and retrotransposition in Barrett's esophagus and esophageal carcinoma. Proc Natl Acad Sci U S A. 2015;112:E4894-900.

151. Sanchez-Luque FJ, Kempen M-JHC, Gerdes P, Vargas-Landin DB, Richardson SR, Troskie R-L, et al. LINE-1 evasion of epigenetic repression in humans. Mol Cell. 2019;75:590-604.

152. Babaian A, Romanish MT, Gagnier L, Kuo LY, Karimi MM, Steidl C, et al. Onco-exaptation of an endogenous retroviral LTR drives IRF5 expression in Hodgkin lymphoma. Oncogene. 2016;35:2542-6.

153. Attig J, Young GR, Hosie L, Perkins D, Encheva-Yokoya V, Stoye JP, et al. LTR retroelement expansion of the human cancer transcriptome and immunopeptidome revealed by de novo transcript assembly. Genome Res. 2019;29:1578-90

154. Bjerregaard B, Holck S, Christensen IJ, Larsson L-I. Syncytin is involved in breast cancer-endothelial cell fusions. Cell Mol Life Sci. 2006;63:1906-11.

155. Strick R, Ackermann S, Langbein M, Swiatek J, Schubert SW, Hashemolhosseini S, et al. Proliferation and cell-cell fusion of endometrial carcinoma are induced by the human endogenous retroviral Syncytin-1 and regulated by TGF-beta. J Mol Med. 2007;85:23-38.

156. Zhou F, Li M, Wei Y, Lin K, Lu Y, Shen J, et al. Activation of HERV-K Env protein is essential for tumorigenesis and metastasis of breast cancer cells. Oncotarget. 2016;7:84093-117.

157. Wiesner T, Lee W, Obenauf AC, Ran L, Murali R, Zhang QF, et al. Alternative transcription initiation leads to expression of a novel ALK isoform in cancer. Nature. 2015;526:453-7.

158. Scarfò I, Pellegrino E, Mereu E, Kwee I, Agnelli L, Bergaggio E, et al. Identification of a new subclass of ALK-negative ALCL expressing aberrant levels of ERBB4 transcripts. Blood. 2016;127:221-32.

159. Nguyen THM, Carreira PE, Sanchez-Luque FJ, Schauer SN, Fagg AC, Richardson SR, et al. L1 retrotransposon heterogeneity in ovarian tumor cell evolution. Cell Rep. 2018;23:3730-40.

160. Medstrand P, Landry JR, Mager DL. Long terminal repeats are used as alternative promoters for the endothelin B receptor and apolipoprotein C-I genes in humans. J Biol Chem. 2001:276:1896-903.

161. Lemaître C, Tsang J, Bireau C, Heidmann T, Dewannieux M. A human endogenous retrovirus-derived gene that can contribute to oncogenesis by activating the ERK pathway and inducing migration and invasion. PLoS Pathog. 2017;13: e1006451.

162. Denne M, Sauter M, Armbruester V, Licht JD, Roemer K, Mueller-Lantzsch N. Physical and functional interactions of human endogenous retrovirus proteins Np9 and rec with the promyelocytic leukemia zinc finger protein. J Virol. 2007; 81:5607-16.

163. Chen T, Meng Z, Gan Y, Wang X, Xu F, Gu Y, et al. The viral oncogene Np9 acts as a critical molecular switch for coactivating $\beta$-catenin, ERK, Akt and Notch1 and promoting the growth of human leukemia stem/progenitor cells. Leukemia. 2013:27:1469-78.

164. Zhou F, Krishnamurthy J, Wei Y, Li M, Hunt K, Johanning GL, et al. Chimeric antigen receptor T cells targeting HERV-K inhibit breast cancer and its metastasis through downregulation of Ras. Oncoimmunology. 2015;4:e1047582.

165. Wang-Johanning F, Rycaj K, Plummer JB, Li M, Yin B, Frerich K, et al. Immunotherapeutic potential of anti-human endogenous retrovirus-K envelope protein antibodies in targeting breast tumors. J Natl Cancer Inst. 2012;104:189-210.

166. Takahashi Y, Harashima N, Kajigaya S, Yokoyama H, Cherkasova E, McCoy JP, et al. Regression of human kidney cancer following allogeneic stem cell transplantation is associated with recognition of an HERV-E antigen by T cells. J Clin Invest. 2008;118:1099-109.

167. Leonova Kl, Brodsky L, Lipchick B, Pal M, Novototskaya L, Chenchik AA, et al. p53 cooperates with DNA methylation and a suicidal interferon response to maintain epigenetic silencing of repeats and noncoding RNAs. Proc Natl Acad Sci U S A. 2013;110:E89-98.

168. Daskalakis M, Brocks D, Sheng Y-H, Islam MS, Ressnerova A, Assenov Y, et al. Reactivation of endogenous retroviral elements via treatment with DNMT- and HDAC-inhibitors. Cell Cycle. 2018;17:811-22.

169. Cuellar TL, Herzner A-M, Zhang X, Goyal Y, Watanabe C, Friedman BA, et al. Silencing of retrotransposons by SETDB1 inhibits the interferon response in acute myeloid leukemia. J Cell Biol. 2017;216:3535-49.

170. Parker BS, Rautela J, Hertzog PJ. Antitumour actions of interferons: implications for cancer therapy. Nat Rev Cancer. 2016; 16:131-44.

171. Loo Yau H, Bell E, Ettayebi I, de Almeida FC, Boukhaled GM, Shen SY, et al. DNA hypomethylating agents increase activation and cytolytic activity of CD8+ T cells. Mol Cell. 2021;81:1469-83.

172. Laumont CM, Vincent $K$, Hesnard L, Audemard É, Bonneil É, Laverdure J-P, et al. Noncoding regions are the main source of targetable tumor-specific antigens. Sci Transl Med. 2018;10:eaau5516.

173. Cherkasova E, Scrivani C, Doh S, Weisman Q, Takahashi Y, Harashima N, et al. Detection of an immunogenic HERV-E envelope with selective expression in clear cell kidney cancer. Cancer Res. 2016;76:2177-85.

174. Waldman AD, Fritz JM, Lenardo MJ. A guide to cancer immunotherapy: from T cell basic science to clinical practice. Nat Rev Immunol. 2020:20:651-68. 
175. Topalian SL, Drake CG, Pardoll DM. Immune checkpoint blockade: a common denominator approach to cancer therapy. Cancer Cell. 2015;27:450-61.

176. Hodi FS, O'Day SJ, McDermott DF, Weber RW, Sosman JA, Haanen JB, et al. Improved survival with ipilimumab in patients with metastatic melanoma. N Engl J Med. 2010;363:711-23.

177. Robert C, Thomas L, Bondarenko I, O'Day S, Weber J, Garbe C, et al. Ipilimumab plus dacarbazine for previously untreated metastatic melanoma. N Engl J Med. 2011;364:2517-26.

178. Sharma P, Hu-Lieskovan S, Wargo JA, Ribas A. Primary, adaptive, and acquired resistance to cancer immunotherapy. Cell. 2017;168:707-23.

179. Weintraub K. Take two: Combining immunotherapy with epigenetic drugs to tackle cancer. Nat Med. 2016;22:8-10.

180. Mehdipour P, Marhon SA, Ettayebi I, Chakravarthy A, Hosseini A, Wang Y, et al. Epigenetic therapy induces transcription of inverted SINEs and ADAR1 dependency. Nature. 2020;588:169-73.

181. Kong Y, Rose CM, Cass AA, Williams AG, Darwish M, Lianoglou S, et al. Transposable element expression in tumors is associated with immune infiltration and increased antigenicity. Nat Commun. 2019;10:5228.

182. Ohtani H, Ørskov AD, Helbo AS, Gillberg L, Liu M, Zhou W, et al. Activation of a subset of evolutionarily young transposable elements and innate immunity are linked to clinical responses to 5-azacytidine. Cancer Res. 2020;80: $2441-50$.

183. Tunbak H, Enriquez-Gasca R, Tie CHC, Gould PA, Mlcochova P, Gupta RK, et al. The HUSH complex is a gatekeeper of type I interferon through epigenetic regulation of LINE-1s. Nat Commun. 2020;11:5387.

184. Kazachenka A, Young GR, Attig J, Kordella C, Lamprianidou E, Zoulia E, et al. Epigenetic therapy of myelodysplastic syndromes connects to cellular differentiation independently of endogenous retroelement derepression. Genome Med. 2019;11:86.

185. Saksouk N, Barth TK, Ziegler-Birling C, Olova N, Nowak A, Rey E, et al. Redundant mechanisms to form silent chromatin at pericentromeric regions rely on BEND3 and DNA methylation. Mol Cell. 2014;56:580-94.

186. Walter M, Teissandier A, Pérez-Palacios R, Bourc'his D. An epigenetic switch ensures transposon repression upon dynamic loss of DNA methylation in embryonic stem cells. Elife. 2016;5:e11418.

187. Lee AK, Pan D, Bao X, Hu M, Li F, Li C-Y. Endogenous retrovirus activation as a key mechanism of anti-tumor immune response in radiotherapy. Radiat Res. 2020;193:305-17.

188. Chew G-L, Campbell AE, De Neef E, Sutliff NA, Shadle SC, Tapscott SJ, et al. DUX4 suppresses MHC class I to promote cancer immune evasion and resistance to checkpoint blockade. Dev Cell. 2019;50:658-71.

189. Smith CC, Beckermann KE, Bortone DS, De Cubas AA, Bixby LM, Lee SJ, et al. Endogenous retroviral signatures predict immunotherapy response in clear cell renal cell carcinoma. J Clin Invest. 2018;128:4804-20.

\section{Publisher's Note}

Springer Nature remains neutral with regard to jurisdictional claims in published maps and institutional affiliations.

Ready to submit your research? Choose BMC and benefit from:
- fast, convenient online submission
- thorough peer review by experienced researchers in your field
- rapid publication on acceptance
- support for research data, including large and complex data types
- gold Open Access which fosters wider collaboration and increased citations
- maximum visibility for your research: over 100M website views per year
At BMC, research is always in progress.
Learn more biomedcentral.com/submissions

